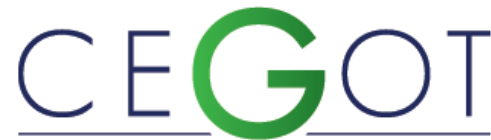

Centro de Estudos de Geografia e Ordenamento do Território
Geografia e Ordenamento do Território, Revista Eletrónica Centro de Estudos de Geografia e Ordenamento do Território http://cegot.org

LOPES, ROSA

Universidade Federal do Rio Grande do Norte - Programa de

Pós-Graduação e Pesquisa em Geografia 590730-100, Natal, Brasil. Rua Paracati, 85. Apto 304 - B rosamrlopes@gmail.com

\section{COSTA, SONEIDE}

Universidade Federal do Rio Grande do Norte - Programa de Pós-Graduação e Pesquisa em Geografia 59076-440, Natal, Brasil. Rua Apolônio de Souza, 1920. Apto 203 soneidemoura.sm@gmail.com

\title{
A configuração da atividade comercial no contexto da expansão do espaço urbano de Natal/RN/Brasil
}

The configuration of commercial activity in the context of the expansion of the urban space of Natal / RN / Brazil

Referência: Lopes, Rosa; Costa, Soneide (2018). A configuração da atividade comercial no contexto da expansão do espaço urbano de Natal/RN/Brasil. Revista de Geografia e Ordenamento do Território (GOT), n. ${ }^{\circ} 13$ (junho). Centro de Estudos de Geografia e Ordenamento do Território, p. 223-246, dx.doi.org/10.17127/got/2018.13.010

\section{RESUMO}

Comércio e cidade relacionam-se intrinsecamente, sejam associados à origem ou aos processos subjacentes impulsionados pela reprodução social no espaço. No artigo, analisase o comércio, no contexto da produção do espaço urbano de Natal/RN-Brasil, nos últimos quatro decênios, considerando a expansão urbana da cidade e a dinâmica do consumo, conforme implementação de tradicionais e modernas formas comerciais. $O$ estudo está ancorado em pesquisa bibliográfica, documental e de campo, cuja investigação revelou que a expansão urbana da cidade se deu acompanhada da descentralização, diversificação e modernização do comércio para além do centro tradicional composto pelos bairros Alecrim, Cidade Alta e Ribeira, corroborando com novas centralidades urbanas.

Palavras-chave: Expansão urbana de Natal. Comércio. Consumo. Novas centralidades.

\section{ABSTRACT}

The commercial activity and the city are intrinsically related. Both may be associated with their origin or the underlying processes driven by social reproduction in space. The objective of the article is to analyze the commercial activity, in the context of the production of the urban space of Natal / RN-Brasil, in the last four decades. It was considered the urban expansion of the city and the dynamics of consumption, according to the implementation of traditional and modern commercial forms. The study is based on bibliographic, documentary and field research. The study revealed that the urban expansion of Natal was accompanied by decentralization, diversification and modernization of commerce in other spaces of the city, besides the traditional center composed by the districts Alecrim, Cidade Alta and Ribeira. This process resulted in the formation of new urban centralities.

Keywords: Urban expansion of Natal. Trade. Consumption. New centralities. 


\section{Introdução}

O comércio acompanha a formação das cidades numa interrelação intrínseca a sua origem, haja vista se mostrar como elemento basilar para a reprodução da vida, pois além de seu caráter econômico, conforma relevante papel nas relações sociais ao se consubstanciar em espaço de encontro e de troca. Para além da lógica fundante, o comércio tem assumido, crescentemente, um lugar de destaque na reprodução do espaço urbano na contemporaneidade, aqui entendida a partir da uma lógica, gestada no seio de uma sociedade orientada não somente pela produção, mas, sobretudo, pelo consumo.

No espaço geográfico, a prática do comércio e, por extensão, do consumo tem motivado várias mudanças que, numa perspectiva dialética, dão e adquirem novos sentidos ao espaço das cidades, conforme as singularidades de cada lugar. Tal fato amplia as perspectivas dos estudos urbanos, haja vista a multiplicidade de formas e a dinamicidade dos processos que encerram problemáticas urbanas cada vez mais complexas e que se relacionam ao comércio, delineando dinâmicas espaciais que revelam como se processa a produção do espaço urbano.

É sob esse olhar geográfico que o texto ora apresentado, analisa o comércio no contexto da produção do espaço urbano de Natal, capital do Rio Grande do Norte, localizada no Nordeste do Brasil. Nos últimos quarenta anos, a cidade vem experimentando uma importante expansão do seu tecido urbano, acompanhada, dentre outros fatores, pelo consórcio de formas comerciais tradicionais e modernas, corroborando com um cenário que tem dado ao consumo um lugar de destaque, quando se pensa na dinâmica do comércio e na reprodução da cidade.

O estudo que se ampara em pesquisa bibliográfica, consorciada ao levantamento de dados estatísticos de órgãos públicos e levantamento de informações primárias, demonstra que, do ponto de vista comercial, foi, somente a partir do final da década de 1970, que as formas comerciais modernas, a exemplo dos supermercados, começaram a surgir na cidade. Ao acompanhar a expansão da cidade, impulsionada pela política habitacional, esses estabelecimentos elegeram como localização, além do centro tradicional de comércio, áreas sob influência desse centro e que tinham relação direta com o adensamento populacional, especialmente, as que foram alvos das políticas habitacional e industrial e mais tarde das intervenções para a promoção da atividade turística. 


\section{A formação de uma cidade terciária: o contexto de Natal/RN}

O comércio mantém uma estreita relação com a fundação e desenvolvimento das cidades, sendo entendido, portanto, como uma das mais importantes atividades a delinear formas e dar vida à cidade. Seja pela relação de origem da cidade através da atividade comercial (VARGAS, 2000) ou pelos processo subjancentes que se consubstanciam na integração entre centro e periferia, e trasformação da paisagem de acordo com o uso do solo pelo comércio, (SALGUEIRO, 1996), ambos, cidade e comércio, devem ser estudados em sua interrelação quando se pretende uma leitura espacial e geográfica da cidade.

Corroborando com a linha de pensamento dos autores supracitados, Ortigoza (2010) enfatiza, não só a implícita relação entre cidade e comércio como também a dinâmica gerada pela combinação de ambos. Na interpretação da autora:

Essas relações entre a cidade e o comércio são dinâmicas e a cidade vai se tornando produto das decisões e das práticas de diversos atores, entre eles os comerciantes, os consumidores, os promotores imobiliários e os produtores/fabricantes. Daí a importância da dimensão espacial na análise do comércio e do consumo (ORTIGOZA, 2010, p. 8-9).

Nesta pesrspectiva, Salgueiro e Cachinho (2009), campartilham da discussão emprendida, reforçando a compreensão sobre as relações entre a cidade e o comércio apontando que a cidade resulta de decisões e práticas dos seus diversos atores que são fortemente relacionadas ao consumo, expressando assim, uma dimensão espacial. Por outro lado, esse espaço serve de contexto e suporte a essas ações, sendo, simultaneamente, mediador das relações e agente de diferenciação.

Dessa relação entendida como dialética, tem-se um amplo campo de possibilidades de estudo, tomando como referência, vários caminhos disciplinares que dão ao tema uma transversalidade cada vez mais acentuada. Na Geografia, tais estudos não são recentes, mas se refizeram ao longo do tempo, revelando abordagens e caminhos metodológicos variados, haja vista, as profundas mudanças instauradas no seio da sociedade contemporânea que inspiraram novas leituras.

A produção da cidade e, por extensão, de um modo de vida urbano em Natal, tem se processado numa relação intrínseca com o aparecimento e multiplicação de formas 
comerciais diversas, modernas e originárias de capitais que atuam em diversas escalas geográficas, especialmente, a partir da década de 1990, quando essa atividade, efetivamente, passa a ganhar expressão na produção do espaço.

A constituição de uma cidade terciária alinhou-se ao processo histórico de urbanização de Natal que ganhou razão de ser no século XX, muito embora sua fundação tenha acontecido ainda no século XVI na conjuntura colonial de ocupação do terriório brasileiro.

O povoamento de Natal esteve atrelado, inicialmente, ao contexto de ocupação dos espaços litorâneos e áreas próximas, a exemplo do que ocorreu em parcela majoritária do território brasileiro. Desta forma Natal, cuja fundação data de 1599, já nasceu cidade, tendo em vista seu relevante papel administrativo e militar para os interesses da colonização portuguesa.

O adensamento populacional de Natal esteve inicialmente concentrado nos bairros que correspondem hoje à Ribeira e à Cidade Alta. Com poucos habitantes e atividades que demandaram uma inexpressiva expansão urbana, a cidade que concentrou, durante três séculos, basicamente as atividades administrativas, a atividade portuária para o escoamento da produção e um incipiente comércio, manteve-se sem alterações consideráveis até o início do século XX.

Conforme afirma Silva (2010), do ponto de vista urbano, Natal é filha do século XX, haja visto que foi somente a partir desse momento que foi possível observar uma dinamização econômica consorciada a um crescimento da infraestrutura urbana com vistas à modernização. Exemplos materiais dessa modernização foram: a incorporação de novos elementos arquitetônicos, urbanísticos e culturais, instalação de redes de saneamento, construção de prédios públicos, pavimentação e drenagem, criação de instrumentos de planejamento urbano e o fortalecimento da imagem da cidade como principal centro urbano norte-rio-grandense, a partir da reforma do porto e da instalação de uma nova estação de trem.

O evento que proporcionou um incremento populacional de maior expressão, acompanhado de um maior adensamento urbano foi a instalação de uma base americana, vizinha à Base Aérea de Natal (BANT), em 1942, por ocasião da Segunda Guerra Mundial, no território que hoje compreende o município de Parnamirim, desmembrado de Natal em 1958. Nesse período o aumento populacional foi de 88,22\%, entre 1940 (54.836) e 1950 
(103.215) (COSTA, 2000), fato que contribuiu para a expansão do comércio e estímulo ao setor imobiliário.

No que pese a relevância desse evento para a urbanização de Natal, ela só se processou, de forma mais contundente, no espaço, com as políticas habitacionais implementadas a partir de 1963 , tendo como elementos de destaque a elaboração do primeiro Plano Habitacional Popular e depois a criação do Banco Nacional de Habitação (BNH), responsável pelo subsídio habitacional que respaldou a expansão de conjuntos habitacionais nas zonas oeste, sul e norte da cidade entre as décadas de 1960 e 1970. Além da política habitacional tem-se, na Zona Norte, a instalação do Distrito Industrial de Natal (DIN) que ampliou a oportunidade de emprego para as pessoas que estavam se instalando nessa área.

Nas décadas seguintes (1980, 1990 e 2000), essa urbanização ganhou expressividade em razão de diversos elementos dentre os quais faz-se importante destacar: a instalação da Região de Produção do Distrito Setentrional da Petrobrás (RPDS), no final da década de 1970 e início da década de 1980; a valorização do espaço em razão da atividade turística, fomentada por políticas públicas de turismo, sendo as mais expressivas: a Política de Megaprojetos Turísticos, implementada no início da década de 1980 e do Programa de Desenvolvimento do Turismo (PRODETUR), desenvolvido entre o final do século XX e início do século XXI.

Conforme pensamento de Cruz (2000) essas políticas de turismo acabaram por apresentar um importante papel na política urbana local, tendo em vista que resultaram em diversas intervenções direcionadas para infraestruturas urbanas que capitalizaram o espaço para os investimentos privados dando sentido à expansão da atividade em Natal.

Esse contundente processo de urbanização de Natal, principalmente a partir da década de 1980 está evidenciado na figura 1, que trata do crecimento urbano da cidade desde a sua fundação até o ano de 2000. 


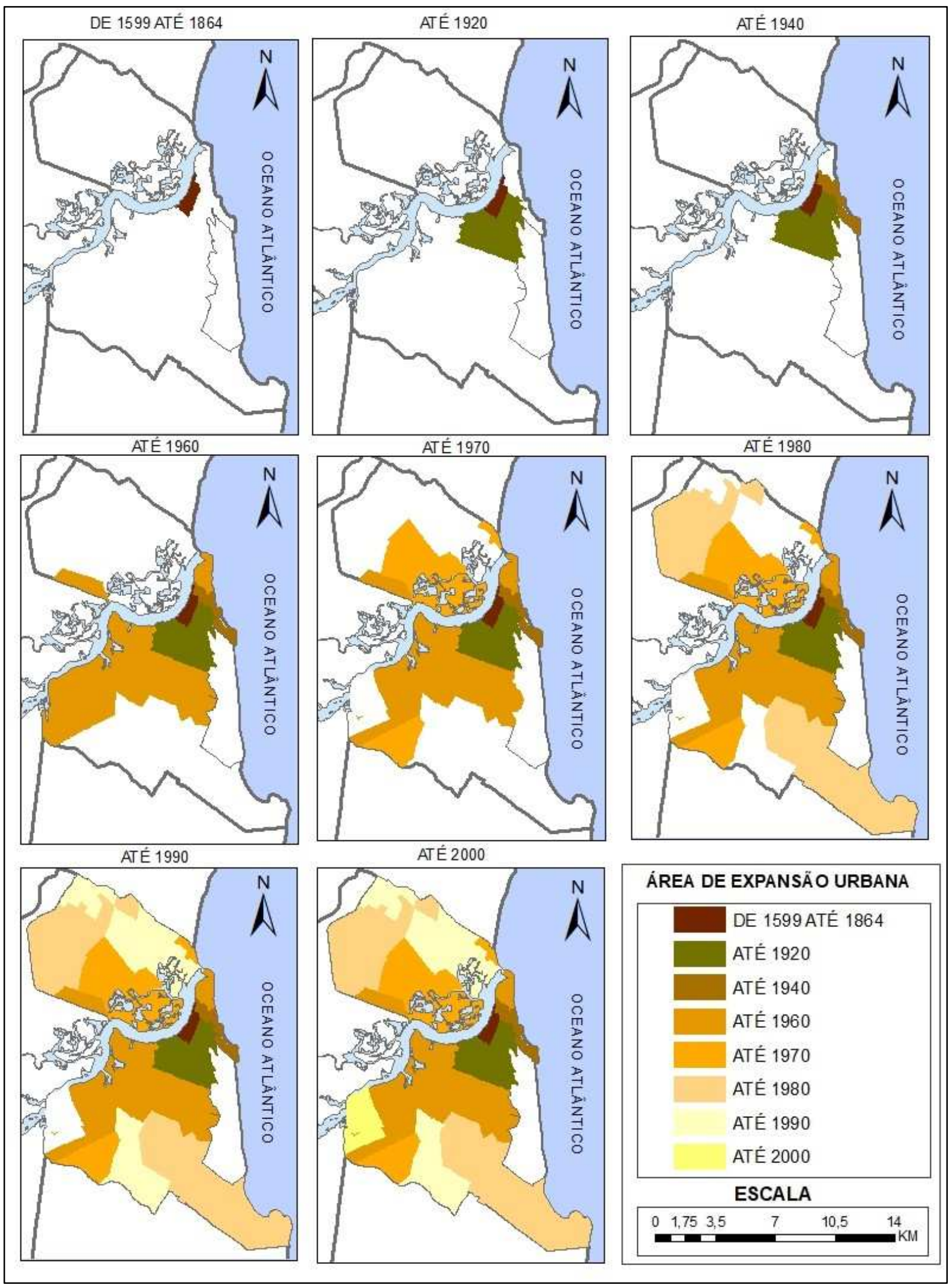

Figura 1 - Expansão urbana de Natal/RN de 1599 a 2000.

Fonte: Natal (2008). (Adaptação das autoras, 2017) 
Para Costa (2000), em sua tese que trata da verticalização de Natal, essas mudanças foram determinantes para ampliar a lógica da espacialidade das atividades terciárias. Segundo o pesquisador: "a ampliação dos serviços em Natal se deu associada ao processo de instalação dos grandes conglomerados industriais, o que contribuiu para atrair pessoas para a cidade e, com efeito, a expansão de seu espaço urbano" (COSTA, 2000, p. 124).

A somatória desses dois tipos de intervenções (industrial e habitacional) propiciou um adensamento populacional em outras áreas da cidade que, por conseguinte, demandou infraestrutura e equipamentos básicos, fazendo surgir, em um primeiro momento, um número crescente de estabelecimentos comerciais e de serviços ao longo das vias expressas de circulação da cidade. Para Gomes, Silva e Silva (2002) essas vias constituem espaço atrativo para as empresas comerciais e de serviços, consubstanciando-se numa combinação de reestruturação viária e relocalização do terciário. Segundo os estudiosos,

Essa nova espacialidade, ou relocalização, não ocorre de maneira espontânea ou mesmo por acaso. Sabiamente, os investimentos privados são instalados nessas vias, visto que no entorno de cada uma delas existe um grande contingente populacional que se torna consumidor das atividades terciárias, garantindo, assim, a reprodução do capital. Além disso, é importante ressaltar que essas vias são facilitadoras do intenso fluxo de população que se desloca pelos diversos trajetos da cidade (GOMES, SILVA, SILVA, 2002, p. 294).

Esse processo sinalizou, do ponto de vista comercial, para uma descentralização espacial dessa atividade, antes concentrada nos bairros de Alecrim, Cidade Alta e Ribeira. Ademais, essas empresas comerciais chegaram no contexto da cidade do Natal, como expressão de uma modernização materializada em novas formas comerciais, como os supermercados, hipermercados e, mais tarde, na década de 1990: shopping centers.

Diferentes processos podem ser observados nessa dinâmica espacial que tem a atividade comercial como elemento de análise. Um deles diz respeito ao surgimento de novas centralidades urbanas no âmbito da expansão urbana de Natal. Essa conjuntura revela a passagem de uma cidade monocêntrica tanto do ponto de vista funcional como do ponto de vista simbólico, para uma cidade de múltiplos centros, haja vista a expansão dessa atividade no âmbito da cidade, acompanhando a ampliação e densificação da malha urbana local.

Tem-se, nesse sentido, um processo de dispersão das atividades comerciais, gerando novas multicentralidades. Para Sposito (2013), a multicentralidade vincula-se à ideia de múltiplos 
centros que não rivalizam entre si, não conformando, portanto, um sistema hierárquico. Associa-se, assim, à coexistência

de mais de uma área de concentração comercial e de serviços nas cidades, influenciando a perda relativa do peso e da importância do centro "principal" em estruturas espaciais tipicamente monocêntricas até então. Assim, o aparecimento de subcentros e de eixos comerciais e de serviços especializados fora do centro tradicional; a implantação de galerias comerciais, reafirmando o centro ou fora dele; ou mesmo o crescimento dessas atividades em áreas pericentrais, antes estritamente residenciais, são formas de multiplicação dos setores que nas cidades concentram atividades, pessoas e fluxos, possibilitando se reconhecer "áreas centrais" (no plural, em função do número delas), ainda que o centro principal continue a exercer a centralidade que estrutura e expressa o conjunto da cidade. (SPOSITO, 2013, p. 74-75).

Associado a essa dinâmica, o centro da cidade passa perder o valor de centralidade que manteve ao longo do processo histórico de construção do espaço. Outras centralidades apontam para uma estrutura urbana mais densa e complexa, dada a natureza diversa das lógicas que compõe a cidade. Tem-se, hodiernamente, uma cidade com mais pessoas, bens e serviços, materialidades e dinâmicas, expressando o que Santos (2014) denominou de fluxos e fixos que se combinam de diferentes maneiras. Mesmo recentes, esses movimentos se expressam no espaço de uma forma marcante e sinalizam condições de centralidade singulares, mas consorciadas, tal como descreve Fernandes (2012) em uma análise sobre centro e centralidade:

[...] pode considerar-se que as cidades conhecem vários centros, seja ao longo da história, seja em simultâneo, na atualidade ou num dado momento. Por outro lado, cada lugar onde se reúnem condições de centralidade, cada centro, tem uma dinâmica que, podendo ser marcada pelo aumento ou diminuição da sua importância relativa, é muito marcada também pela continuidade daquela parcela de cidade ao longo dos muitos anos que viveu, inserida na história da cidade (e refletindo a história / participando na história da sociedade), umas vezes mais central, outras vezes mais periférica (FERNANDES, 2012, p. 34).

Nesse sentido, destaca-se a ocorrência de uma centralidade relativa ao centro histórico que é por extensão simbólico e funcional, consorciando-se a outras centralidades mais recentes que resultaram do próprio crescimento da cidade. Todas elas se inserem em um contexto urbano regional, dada a metropolização de Natal, sendo, portanto, complementares. Contudo, essas centralidades mantêm um movimento próprio que as singularizam de acordo com os diferentes usos da cidade, mudando de valor ao longo do tempo, como ocorreu no centro histórico da cidade. Este vem perdendo importância diante do 
surgimento de novos espaços de uma vitalidade acentuada, a exemplo das principais vias expressas de circulação onde se instalaram muitas empresas comerciais e de serviços de grandes dimensões como os hipermercados, supermercados e shopping centers, sinalizando para uma dinâmica citadina mais intensa e que dá ao comércio um lugar de destaque.

O surgimento dessas novas centralidades, alinha-se aos processos históricos verificados no decorrer do processo de expansão urbana da cidade, conforme informação supracitada. Tais processos deixaram marcas na paisagem urbana de Natal e afirmaram, por intermédio das diferentes práticas sociais, novas dinâmicas espaciais. Ao se expandir para além das áreas tradicionais, o comércio acompanhou a expansão urbana, se fixando ao longo das vias expressas de circulação à medida que elas foram se consolidando e dando sentido ao crescimento do tecido urbano, marcado especialmente, pelas intervenções decorrentes da política habitacional e industrial, esta última na Zona Norte da cidade que se inicia na década 1970, mas se intensifica na década de 1990.

O turismo, aparece de forma mais acentuada, a partir da década de 1990, como resultado de uma política responsável por importantes interveções de natureza urbana, demarcando um espaço de uso turístico acentuado, que congregou uma série de serviços e atividades comerciais e que tem uma relevante representatividade para a dinâmica urbana citadina. Considerando esse cenário, tem-se uma cidade que cresce e se consolida, tomando como referência um tempo relativamente recente se comparado à sua fundação, tendo o comércio um importante papel nesse configuração espacial.

\subsection{A atividade comercial em Natal/RN: um cenário recente}

Nas últimas quatro décadas a atividade comercial de Natal tem apresentado mudanças significativas nas quatro últimas décadas. Evidencia-se, nesse sentido, uma modernização das formas comerciais com repercussões espaciais, que vão além da mera distribuição e diversificação comercial. Elas sinalizam a habilidade que têm para valorizar o espaço, tornando-o mercadoria, especialmente, aquelas orientadas em função da atividade turística e isso se consubstancia como um novo momento da acumulação capitalista. Por outro lado, de forma combinada e numa perspectiva dialética, esse espaço apresenta-se por intermédio de amenidades que garantem valor a essa mercadoria. Nesses termos, para além de um 
valor de uso, o espaço torna-se mercadoria, adquirindo um valor de troca cada vez mais relevante em sua reprodução.

Esse valor de troca se sobreleva não somente tendo o turismo como atividade emblemática, mas, também, outras práticas eventuais ou não. Um exemplo é a capitalização do espaço para práticas de lazer e para dar guarida aos eventos esportivos mundiais e socioculturais como espetáculos, feiras de negócios, dentre outros, o que tem proporcionado, nas palavras de Harvey (2005) o empresariamento do espaço, fruto dessa valorização crescente.

No tocante ao número de empresas de natureza comercial, os dados do Cadastro Central de Empresas (IBGE), associados aos da Tributação do Estado do Rio Grande do Norte, revelam que o incremente da atividade comercial em Natal é relativamente recente, tendo se acentuado a partir da década de 1980, quando apresentou um aumento de 2.272 empresas, passando de 601 empresas em 1970 para 2873 em 1980 (Gráfico 1). Esse dado revela uma cidade que ganha uma maior representatividade urbana, em consórcio com um terciário pujante e certamente definidor de vários processos e formas que à história da cidade se associam. Corroborando essa informação, os dados mostram um total de 12.466 estabelecimentos comerciais registrados em 2016, denotando um crescimento de mais de 400\% em relação à década de 1980.

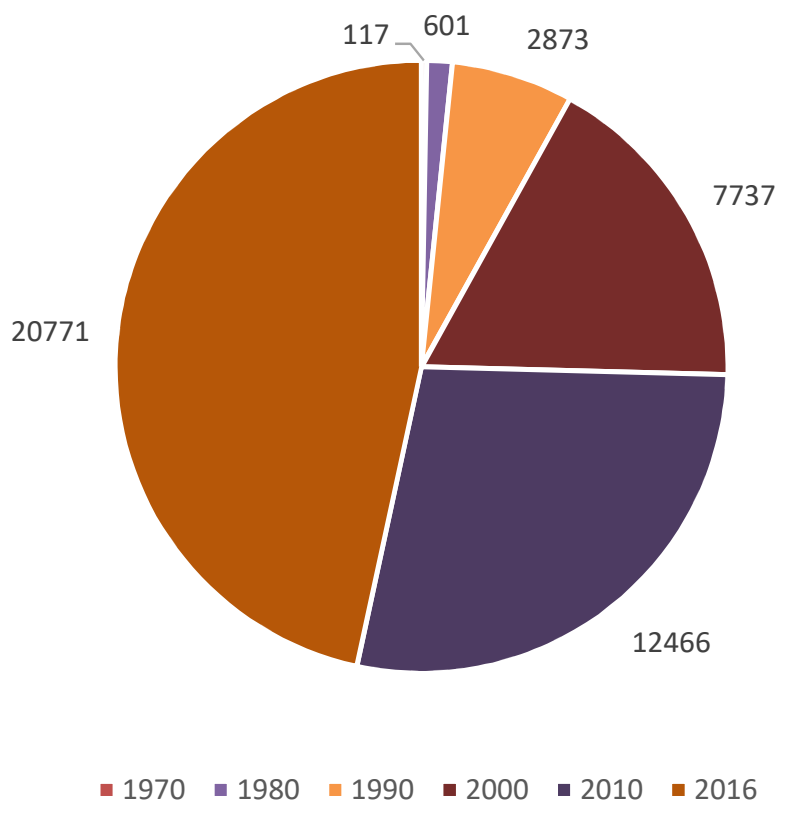

Gráfico 1 - Empresas comerciais por ano de fundação.

Fonte: IBGE, SIDRA, Cadastro Central de Empresas, 2006; Tributação do Estado, 2017. 
O gráfico 01 ratifica ainda que de uma forma geral que o crescimento do número de empresas se deu de forma acentuada a partir da década de 1980, quando se observa uma expansão da atividade comercial em Natal, acompanhando, por seu turno, a expansão urbana da cidade.

Essa conjuntura se alinha à tendência brasileira que detém, do ponto de vista econômico, um número expressivo de empresas nos segmentos de comércio e serviços, que por sua vez segue uma tendência mundial marcada pela economia terciária. Um dado que ratifica essa informação é o de que, no país, a cada dez empresas formalizadas, oito compõem o setor terciário (BRASIL, 2013).

No caso de Natal, o Cadastro Empresarial do Rio Grande do Norte, construído pelo Serviço Brasileiro de Apoio às Micro e Pequenas Empresas (SEBRAE), aponta que, do ponto de vista econômico, no ano de 2010, a cidade concentrou parcela majoritária de seus empreendimentos no comércio e nos serviços. São 22.048 estabelecimentos comerciais e de serviços, distribuídos entre formais e informais, em contraponto a um total de 2.048 de empresas de outros segmentos econômicos (ver gráfico 2). Em termos percentuais o terciário detinha $90,7 \%$ de todos os negócios localizados em Natal, confirmando uma característica fortemente arraigada em um terciário relativamente recente, dado o histórico dessa atividade no contexto da cidade.

No comparativo com o Rio Grande do Norte e ao se considerar os anos de 2010 a 2013 percebe-se que, com pequenas variações, mais de $26 \%$ de todo comércio do Rio Grande do Norte está concentrado na cidade do Natal (Gráfico 3). Este percentual está em proporcionalidade com a população da referida cidade, posto que, de acordo com o IBGE (2010), Natal registrou um total de 803.811 mil habitantes, correspondendo a $25,3 \%$ do total da população do estado, que é de 3.168 .133 habitantes. 


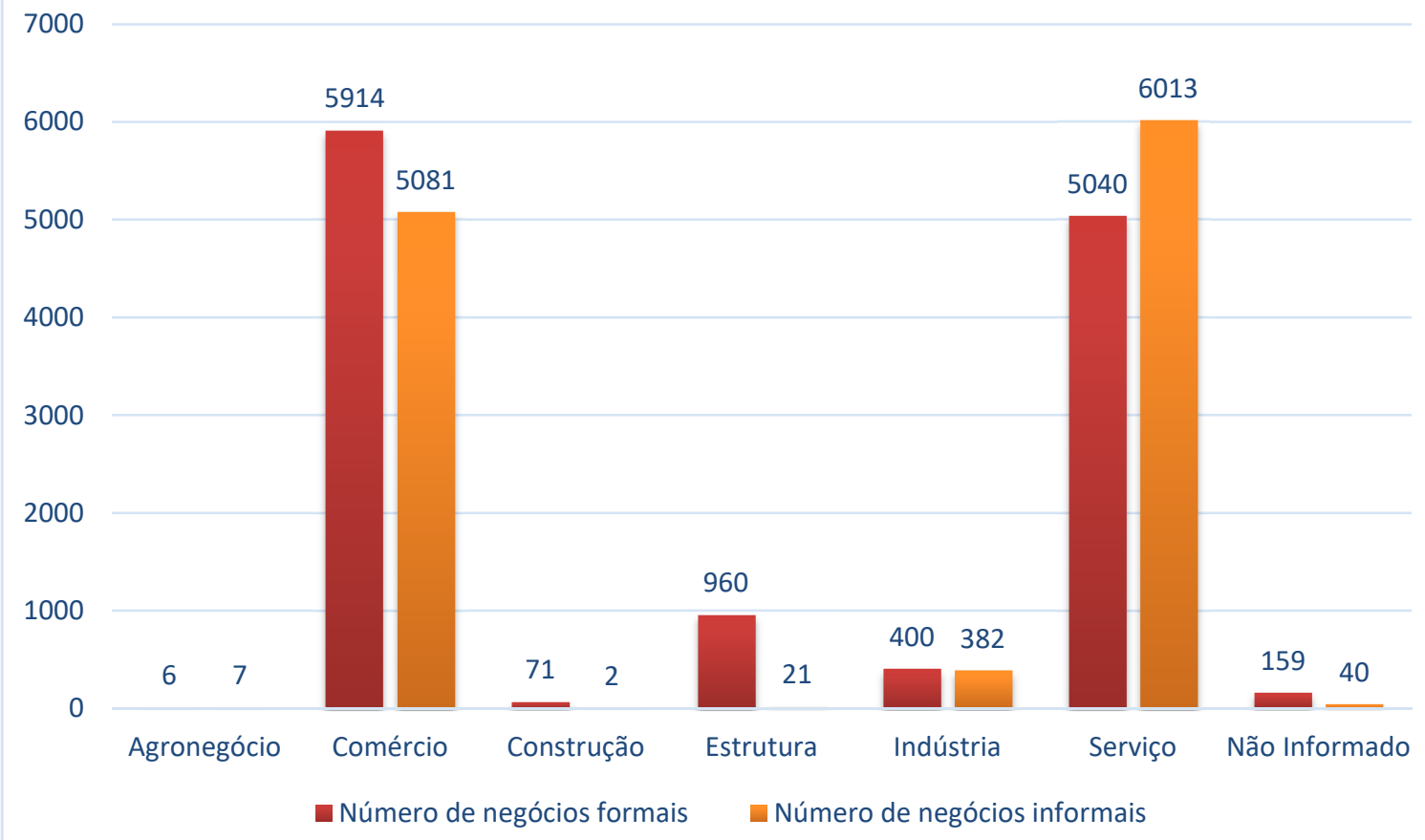

Gráfico 2 - Natal - Número de negócios (2010).

Fonte: SEBRAE, 2010.

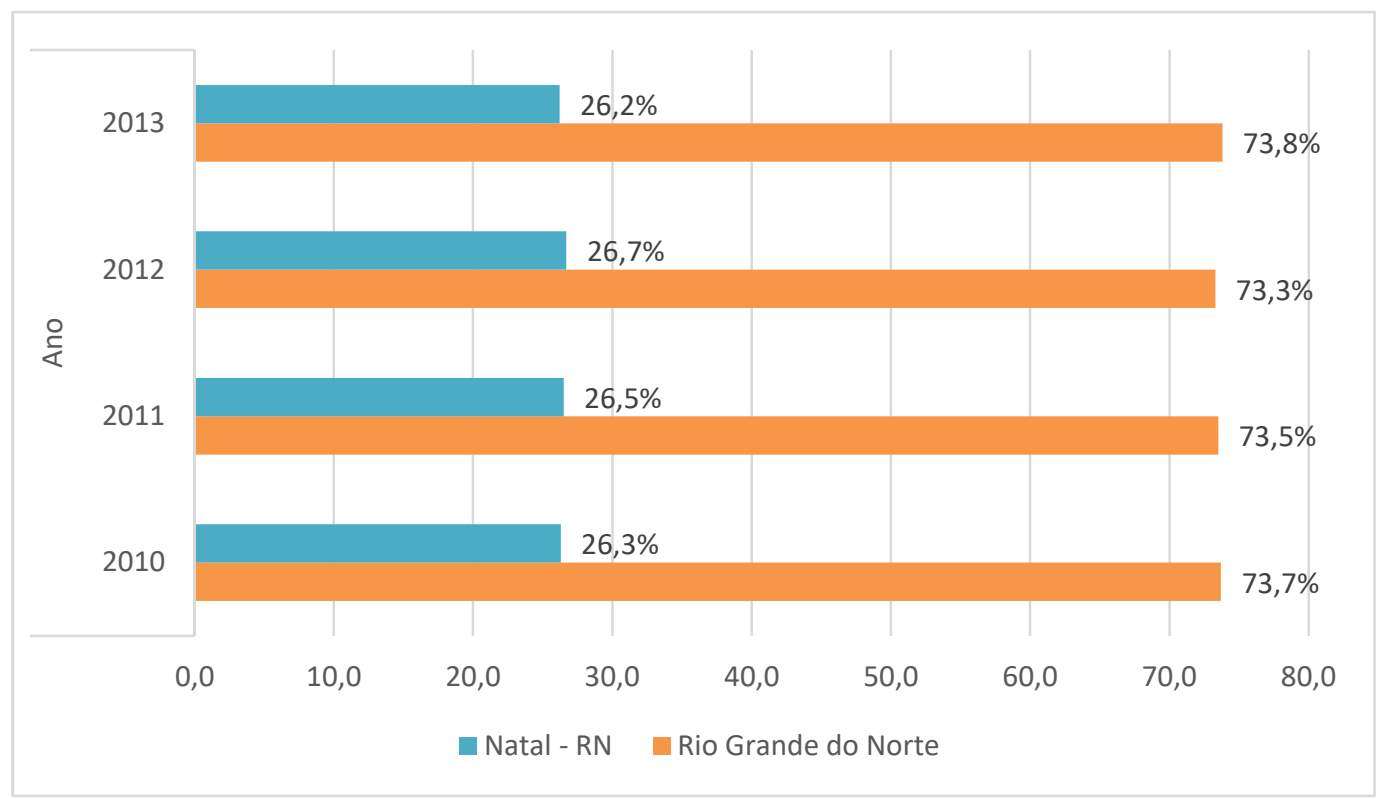

Gráfico 3 - Comparativo percentual do comércio entre Natal e Rio Grande do Norte (2010-2013) Fonte: IBGE, Cadastro Central de Empresas, 2016.

Esses estabelecimentos comerciais encontram-se distribuídos por toda a cidade, mas concentram-se em determinados espaços, justificando, portanto um fluxo diário expressivo de pessoas, meios de transportes públicos e privados, além de mercadorias que abastecem essas áreas. No contexto espacial, é possível observar diferentes lógicas 
de localização que explicam e encontram justificativa nas práticas sociais representativas desses subespaços citadinos, conforme análise seguinte.

\section{As formas comerciais no contexto espacial da cidade}

Como visto na seção anterior, no transcorrer das últimas quatro décadas, Natal se colocou como importante centro terciário, seja numa perspectiva intraurbana ou urbano-regional. 0 comércio, tem-se apresentado como atividade de relevo, influenciando, sobremaneira, a produção do espaço natalense e essa influência se traduz nas diferentes formas comerciais que a cidade vem abrigando ao longo do tempo.

Para a compreensão do que seriam as formas comerciais, toma-se como referência o entendimento de Pintaudi ao ressaltar que são "antes de mais nada, formas sociais" (2013, p. 162). Numa perspectiva dialética, as relações sociais produzem formas comerciais que, por sua vez, inspiram as relações sociais.

Transportando essa compreensão para o estudo ora apresentado, defende-se a ideia de que as formas comerciais no espaço, identificadas e apresentadas na sequência, resultam de uma dinâmica própria das relações sociais que deram significado à produção do espaço, recebendo das formas comerciais aí estabelecidas, signos que particularizam a cidade e suas relações.

A expressiva participação do comércio na produção do espaço urbano de Natal na contemporaneidade, permite algumas inferências importantes e uma delas é a de que se vislumbra a emergência de um sistema comercial moderno a partir da década de 1980 quando se observa uma revolução comercial se generalizando por muitos países. Alguns aspectos dessa revolução são estudados por Fernandes, Cachinho e Ribeiro (2000) em um texto sobre o comércio tradicional no contexto urbano e relacionam-se às mudanças ligadas aos novos formatos de estabelecimentos comerciais, às formas de venda, ao perfil dos comerciantes, às estratégias de gestão das empresas, aos padrões de localização e ao significado dos espaços comerciais.

Assim, apoiada por mudanças estruturais na sociedade, tais como: o aumento dos rendimentos familiares, a crescente integração da mulher ao mercado de trabalho, o 
aumento do uso de veículos automotores e as mudanças nos padrões de consumo, tem-se o surgimento de grandes superfícies comerciais, o rompimento de tradicionais padrões de localização espacial do comércio e de gestão desses empreendimentos, além de uma relação mais afinada do espaço de venda com o consumidor, haja vista que de meros espaços de troca, os estabelecimentos tornam-se espaços mercadorias de experiência de consumo. Contudo, vale destacar que os sistemas tradicionais de comércio resistem às mudanças verificadas no transcurso das quatro últimas décadas, muitas vezes até se complementando aos modernos no contexto urbano. Além do exposto, os estabelecimentos comercias podem, em alguns casos, apresentar característica modernas e tradicionais como sugere Fernades, Cachinho e Ribeiro (2000, p. 13): “muitas vezes, a realidade é bem mais complexa podendo-se encontrar tanto num lado como no outro situações de autêntica reversibilidade".

No que pese a relevância de formas comerciais tradicionais historicamente presentes em Natal, a exemplo dos mercados públicos e feiras livres, são as formas comerciais modernas, traduzidas em shopping centers, supermercados e hipermercados que dão sentido à espacialização da atividade comercial que se articula à conformação urbana da cidade do Natal.

As formas modernas produzem e são produzidas pela cidade sob uma lógica material que mantém uma repercussão ideológica delineada por uma sociedade moderna que mantém em suas relações uma integração pelo mercado, sujeitando crescentemente os espaços à ideia da troca. Conforme salienta Pintaudi, "a concepção do mundo é aquela veiculada pela publicidade da mercadoria e os hipermercados e shoppings centers são os lugares que melhor traduzem a nova centralidade para a troca de mercadorias" (2013, p. 157).

As formas comerciais tradicionais são sujeitadas aos interesses capitalistas, quando facilmente são constatadas intervenções que lhes atribuem novos significados, novas roupagens no sentido de espetacularizar o conteúdo social desses espaços. Em Natal, essa característica se verifica ainda de forma bastante pontual e relaciona-se, principalmente, ao turismo que tem se apropriado de parcelas do espaço da cidade, valorizando diferentemente esses espaços.

Outro aspecto de grande monta diz respeito ao intercâmbio de influências próximas e distantes que marcam a conjuntura de aparecimento e desenvolvimento dessas formas 
comerciais. Elas não existem fora de um contexto socioeconômico e político, muitas vezes ditado por uma ordem distante. Ademais, mantém relação umas com as outras no contexto intraurbano, não podendo jamais serem tomadas a análise isoladamente.

Espacialmente o comércio de Natal se encontra, nos dias atuais, presente em todas as suas regiões administrativas, algumas vezes, ao definir centralidades importantes, outras, ao determinar subcentralidades no contexto da cidade. Grosso modo, apresenta-se três espacialidades marcadas por formas comerciais de expressão para o contexto da cidade (ver mapa 1). Todas elas se relacionam ao comércio varejista, haja vista ser essa tipologia a mais representativa.

Define-se resumidamente essas espacialidades como:

a) Áreas tradicionais de comércio;

b) Áreas comerciais sob influência da atividade turística;

c) Áreas comerciais sob a lógica das vias expressas de circulação.

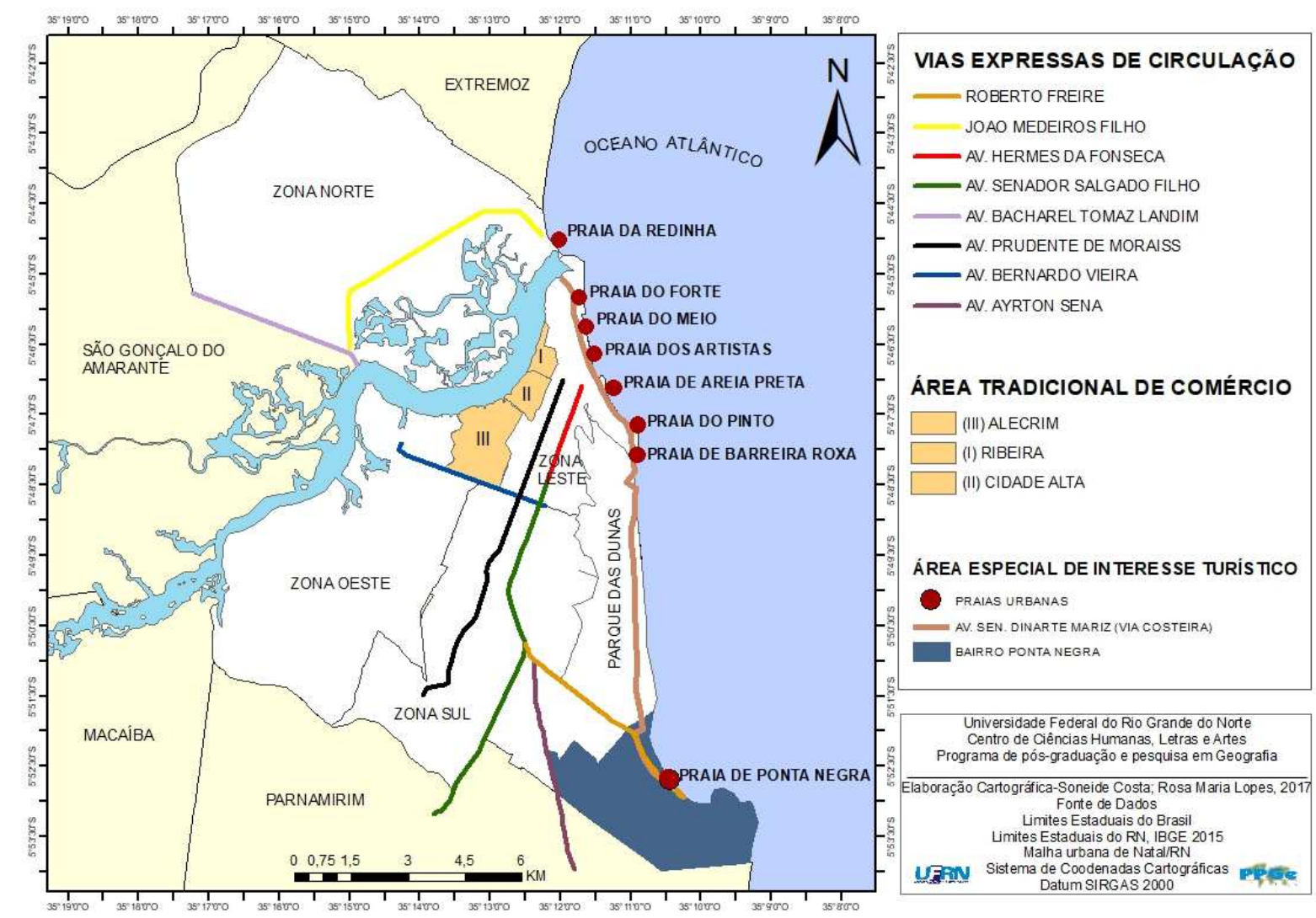

Mapa 1 - Espacialialização do comércio em Natal/RN.

Fonte: IBGE (2015). Malha urbana de Natal/RN

Elaboração: Soneide Moura; Rosa Maria Lopes, 2017 
A espacialidade de maior expressão no âmbito da cidade centra-se nas áreas entendidas como tradicionais de comércio. O sentido tradicional reporta-se ao contexto histórico de produção do espaço urbano de Natal. Assim, a leitura é a de que, do ponto de vista histórico, o comércio ganhou espaço nessa área, aqui delimitada pelos bairros do Alecrim, da Cidade Alta e da Ribeira que têm no comércio varejista uma importante representação.

Esses bairros, com destaque para o Alecrim (detentor do maior número de estabelecimentos comerciais), concentram parcela significativa do comércio varejista da cidade. Mesmo com a diversificação, a modernização e o surgimento de novas formas comerciais em outras áreas citadinas, o comércio dessas áreas mantém uma importante centralidade no âmbito de Natal, na medida em que continua atraindo um fluxo intenso de consumidores.

As áreas comerciais produzidas sob influência da atividade turística referem-se aos enclaves ${ }^{1}$ muito fortemente apropriados para e pelo turismo. Correspondem, assim, aos espaços que compreendem à orla marítima da cidade com destaque para o bairro de Ponta Negra e a Avenida Senador Dinarte Mariz (Via Costeira) onde se tem a maior concentração de estabelecimentos comerciais para atender à demanda turística. Mas é possível também observar um comércio representativo dessa atividade nas praias urbanas de Areia Preta, Praia do Forte, Praia do Meio e Redinha. Contudo, esse comércio limita-se quase que exclusivamente à área que tem contato direto com a orla marítima e se caracteriza, sobretudo, pela forte presença da informalidade que se materializa com a prática de vendedores ambulantes e barraqueiros.

As áreas comerciais sob a lógica das vias expressas de circulação (ver mapa 2), correspondem às principais avenidas que interligam bairros da Zona Sul e da Zona Norte ao centro da cidade. Nesse contexto, tem-se: as avenidas Senador Salgado Filho-Hermes da Fonseca, Bernardo Viera, Prudente de Morais, Ayrton Sena e Roberto Freire, na Zona Sul da cidade, e as avenidas Bacharel Tomás Landim e Dr. João Medeiros Filho, na Zona Norte.

Nessas vias, é possível verificar a maior ocorrência de formas comerciais modernas. Nelas se localizam todos os shopping centers da cidade, hipermercados, atacarejos ${ }^{2}$ e os principais

\footnotetext{
${ }^{1}$ Segundo Caldeira (2000, p.258), enclaves são "propriedades privadas para uso coletivo e enfatizam o valor do que é privado e restrito ao mesmo tempo que desvalorizam o que é público e aberto na cidade.

${ }^{2}$ Atacarejo é uma modalidade de venda atacadista tanto para o varegista quanto para o consumidor final.
} 
supermercados e redes de franquias. Além dessas formas comerciais, é possível encontrar concessionárias de veículos, lojas de decoração, de alimentação, eletrônicos, vestuário, alimentação, calçados e acessórios, produtos de beleza e serviços variados.
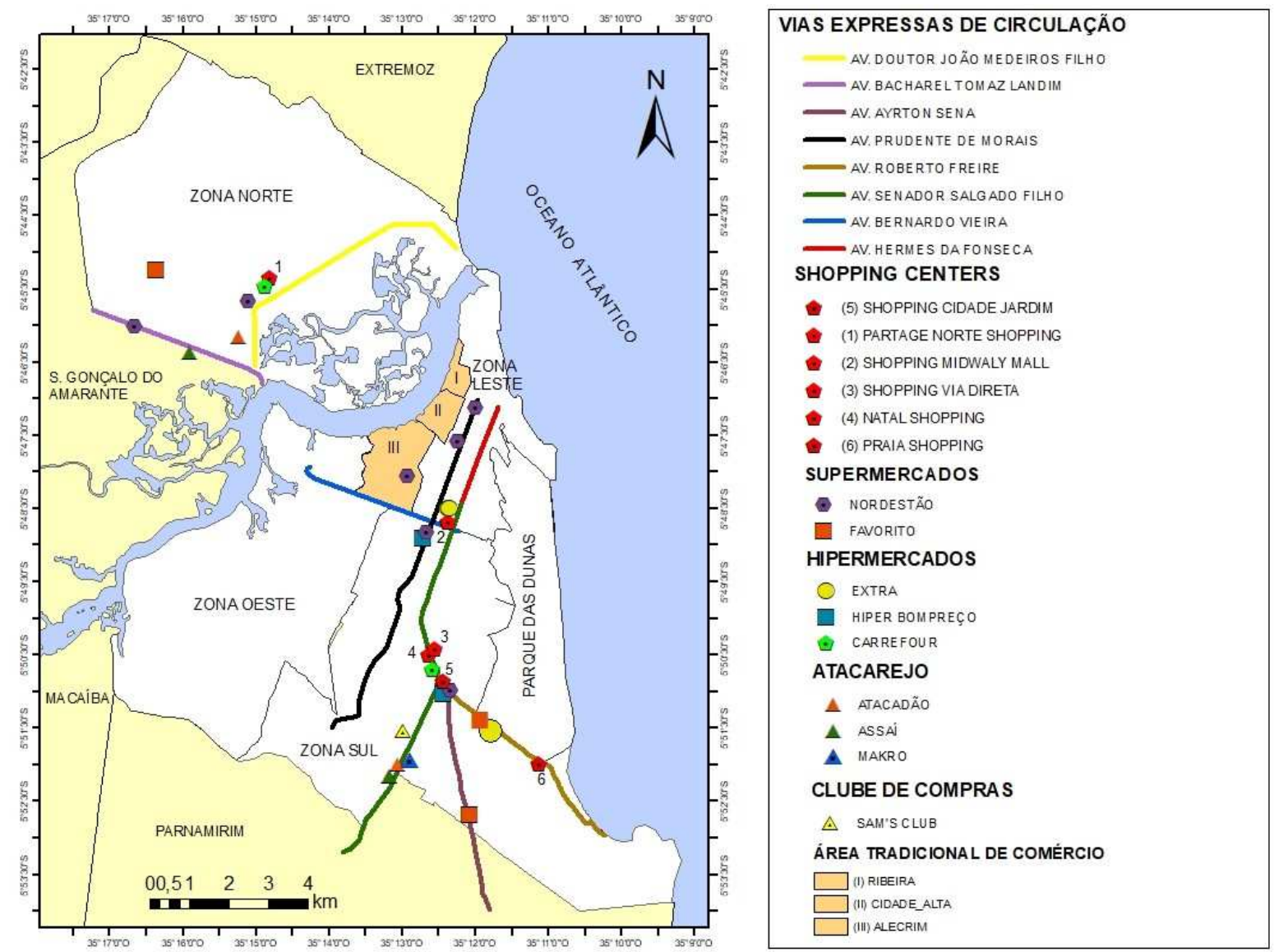

Mapa 2 - Vias expressas de circulação.

Fonte: IBGE (2015). Malha urbana de Natal/RN

Elaboração: Soneide Moura; Rosa Maria Lopes, 2017

Com que tange à distribuição espaço-temporal dessas novas formas comerciais no âmbito da cidade, percebe-se que como resultado da expansão urbana de Natal a partir da década de 1970, mas também, de mudanças no processo produtivo, em conformidade com as novas exigências da produção capitalista, os primeiros supermercados foram criados na cidade. Forma comercial de concepção americana do final do século XIX, o supermercado surgiu, trazendo uma técnica de venda que revolucionou o comércio varejista: o autosserviço. Ao aproximar o produto do consumidor, essa forma comercial apresentou-se, a partir de uma nova concepção de organização interna e apresentação dos produtos. 
Originada majoritariamente nos EUA, teve sua difusão para outros países, no período posterior à Segunda Guerra Mundial. No Brasil, esse tipo de estabelecimento começou a ser implantado na década de 1950 com a inauguração do primeiro supermercado em 1953, na cidade de São Paulo (PINTAUDI, 1984).

As duas primeiras unidades supermercadistas que se instalaram em Natal foram o Mini Preço, em novembro de 1969, e o Nordestão, em janeiro de 1972 (QUEIROZ; SOUZA, GOUVINHAS, 2008). Contudo, na década de 1970, outros estabelecimentos de capital local também foram abertos em Natal. São exemplos: Superbox, Mini Box e Superete Queiroz, Jardinense, São José e, mais tarde, a rede Sirva-se Supermercados. De todos esses, o Nordestão foi único que conseguiu se manter no mercado, inclusive, ampliando sua atuação para todas as zonas administrativas da cidade, nas décadas posteriores.

Na década de 1980, Natal viu adentrar o capital externo nos ramos do comércio varejista local, com a chegada dos hipermercados e shopping centers. Os hipermercados tiveram origem na década de 1960, na França e chegaram ao Brasil na década seguinte (1970), tendo sua primeira unidade instalada em Natal, em 1982 (Hiper Bompreço), na Avenida Prudente de Morais. Suas unidades posteriores (todas elas localizadas em vias expressas de circulação) foram inauguradas nas décadas seguintes.

Assim, os hipermercados ganharam espaço instalando-se ao longo das vias expressas de circulação. Diferentes dos supermercados, esse tipo de comércio pressupõe uma superfície maior, concentrando uma grande variedade de produtos desde gênero alimentício, passando por livraria, eletrodomésticos, vestuário, decoração, autopeças e outros. Representativo dessa forma comercial é o Carrefour, inaugurado em 1997, na Avenida Senador Salgado Filho e em 2006 na Avenida Dr. João Medeiros Filho. O grupo Pão de Açúcar volta a Natal, em 2005, com a instalação do hipermercado Extra, no shopping Midway Mall, em 2007, na Avenida Engenheiro Roberto Freire e, em 2012, na Avenida Maria Lacerda Montenegro.

Os shopping centers chegaram ao Brasil na década de 1960, tendo sua primeira unidade em solo natalense, em 1984, com a instalação do Shopping Cidade Jardim, no Bairro de Capim Macio, marcando uma tendência à modernização do comércio varejista natalense, 
descentralização e diversificação das formas comerciais no contexto da cidade e à mudança de hábitos de consumo da população.

Na década de 1990, essas formas comerciais expandiram-se no âmbito da cidade, fazendose presentes em seus principais eixos viários. Em 1992, foi inaugurado o Natal Shopping e, em 1995, o Via Direta, ambos localizados na Avenida Senador Salgado Filho e interligados por uma passarela. Em 1997, foi a vez da inauguração do Praia Shopping, na Engenheiro Roberto Freire, denotando a existência de uma demanda muito relacionada à atividade turística no Bairro de Ponta Negra, que já vinha se processando desde os investimentos públicos e privados realizados, a partir do final da década de 1970.

Nos anos 2000, a cidade recebeu o Midway Mall (2005), shopping center localizado no cruzamento entre as duas maiores avenidas da cidade, em termos de fluxo: a Senador Salgado Filho e Bernardo Vieira. Como o próprio nome sugere, Midway Mall localiza-se no "meio do caminho", pois se encontra instalado no entroncamento de acesso a todas as zonas administrativas de Natal. Esse é o maior shopping center em termos de superfície, o único com estacionamento gratuito e que tem uma diversidade de estabelecimentos que atendem a uma demanda variada de público. Certamente foi o empreendimento comercial de maior envergadura para a dinâmica comercial da cidade, proporcionando impacto tanto para as áreas tradicionais de comércio, como para os novos empreendimentos comerciais da cidade. No ano de 2007, o Bairro Potengi, na Zona Norte da cidade passou a abrigar o Partage Norte Shopping, localizado em mais uma via expressa de circulação da cidade, a Avenida Dr. João Medeiros Filho.

Os anos 2000 assistiram, também, a chegada de outras grandes superfícies comerciais representadas pelo comércio atacadista. São exemplos: Makro, Atacadão, Sam's Club, Assaí, Super Fácil e Maxx Atacado, estes dois últimos localizados no município limítrofe de Parnamirim. A instalação desses empreendimentos atacadistas marca a inserção, de forma mais acentuada, do capital nacional e internacional no território natalense, embora seja possível identificar outras formas comerciais de grandes dimensões na década de 1990, como o Carrefour.

Sendo assim, somente nos anos 2000 que esse tipo de capital ganha notoriedade com a instalação de empresas comerciais (shopping centers, hipermercados, supermercados, lojas 
de eletrodomésticos) geridas por grandes grupos de capital nacional como Grupo Pão de Açúcar e de capital internacional como o grupos Carrefour e Walmart. Seguindo a mesma lógica, os shopping centers da cidade, com exceção do Shopping Via Direta, Praia Shopping e Shopping Cidade Jardim, são pertecentes a empresas que atuam no mercado nacional conforme informação do quadro 1.

\begin{tabular}{|l|l|l|}
\hline \multicolumn{1}{|c|}{ GRUPO } & \multicolumn{1}{|c|}{ SEDE DO GRUPO } & \multicolumn{1}{|c|}{ EMPRESAS COMERCIAIS } \\
\hline Walmart & EUA & $\begin{array}{l}\text { - Hiperbompreço } \\
- \text { Sam's Clube } \\
- \text { Bompreço }\end{array}$ \\
\hline Carrefour & França & $\begin{array}{l}\text { - Carrefour } \\
- \text { Atacadão }\end{array}$ \\
\hline SHV Holdings N.V & Holanda & - Makro \\
\hline Pão de Açúcar & Brasil/São Paulo & $\begin{array}{l}\text { - Extra } \\
\text { - Assaí } \\
\text { - Maxx Atacado } \\
\text { - Casas Bahia }\end{array}$ \\
\hline Guararapes & & - Midway Mall \\
\hline Ancar Ivanhoe e BRMalls & Brasil/São Paulo & - Natal Shopping \\
\hline Partage & Brasil/São Paulo & - Partage Norte Shopping \\
\hline Capuche & Brasil/Rio Grande do Norte & - Praia Shopping \\
\hline Medeiros & Brasil/Rio Grande do Norte & - Shopping Via Direta \\
\hline Veríssimo \& Filhos & Brasil/Rio Grande do Norte & - Shopping Cidade Jardim \\
\hline Nordestão & Brasil/Rio Grande do Norte & $\begin{array}{l}\text { - Supermercados Nordestão } \\
\text { - Super Fácil }\end{array}$ \\
\hline
\end{tabular}

Quadro 1 - Principais grupos em atuação na atividade comercial em Natal/RN. Fonte: Pesquisa de campo, 2017.

Em que pese a relevância dessa espacialização, evidencia-se que no contexto da expansão da cidade, possibilitada dentre outros fatores pela construção de conjuntos habitacionais ${ }^{3}$, os bairros atendidos por esta política passaram a abrigar, também, estabelecimentos comerciais e de serviços para atender, a priori, a demanda básica de consumo da população como alimentação, vestuário, medicamentos e serviços básicos de reparação de modo geral.

Nos bairros, o comércio surgiu em concomitância com a moradia, consubstanciados pela própria razão de ser da relação entre ambos. Assim como em outros espaços, as redes associativistas, entendidas por Pessoa (2015) como uma organização comercial em que o

\footnotetext{
${ }^{3}$ No Brasil a expressão conjunto habitacional significa um processo de produção habitacional de interesse social realizada com recursos públicos do Sistema Financeiro de Habitação (SFH).
} 
associado encontra-se subordinado a uma gestão compartilhada orientada pelos princípios do associativismo e que são delineados no âmbito da associação a qual pertence, marcaram presença, também em alguns desses bairros, com os segmentos farmacêutico e supermercadista.

O comércio que a princípio se conformou com o propósito de atender a demanda do bairro ganhou maior notoriedade nas últimas duas décadas, de modo a se configurar, na contemporaneidade, como espaços de referência comercial popular, não só para a população de sua localização, mas também para outras áreas de Natal. Essa atividade mantém uma dinâmica comercial no âmbito da cidade, no entanto torna-se emblemática para o lugar pela função social de proximidade que exerce. De acordo com Barreta, (2012, p.14), quando discutiu a relação entre o centro das urbes e o comércio de proximidade em Portugal "o conceito de comércio de proximidade retrata o comércio que está próximo da sua procura, não só fisicamente, mas também, e principalmente, social, cultural, patrimonial e comercialmente". A discussão desenvolvida por Barreta (2012) fornece subsídios para a compreensão da realidade em questão, visto que a função social de proximidade do comércio nos espaços em evidência tem a função social de anular grandes distâncias para a população que mora próximo a esse comércio e ainda proporciona relações de vizinhança, confiabiabilidade e maior sociabilidade promovidos pelo comércio.

O comércio de bairro configura centralidades menores, mas que marcam, também, um processo que contribui para uma diminuição relativa do papel do centro tradicional, retirando sua exclusividade comercial no âmbito da cidade, o que está definido neste trabalho como desconcentração espacial da atividade comercial. Esse tipo de espacialidade é composto por estabelecimentos de pequeno porte, muitos dos quais direcionados ao atendimento de necessidades básicas (alimentação, vestuário, papelaria) e de base familiar. Além desses, observa-se, em muitos bairros da capital, uma crescente ocorrência de supermercados organizados em redes associativistas locais e regionais como Rede Mais, Supercop, Super Show, Parceiros da Economia, Nossa Gente e Unisuper.

Observa-se, assim, que as formas comerciais da forma como se espacializam, acompanham dinâmicas urbanas e são reflexos dessas dinâmicas, numa perspectiva dialética. Elas expressam práticas sociais que marcaram materialmente o espaço ao longo de sua história recente, delimitando espaços animados, muito acentuadamente, pela atividade terciária. 


\section{Considerações Finais}

Originária do século XVI, Natal teve seu processo de urbanização expressivamente consolidado no século $\mathrm{XX}$, por ocasião da implementação dos equipamentos de infraestrutura urbana modernos que serviram de substrato para que a cidade se firmasse como centro urbano de influência para o estado. A infraestrutura que permitiu condições para a produção do espaço da cidade e sua consequente reprodução, é tributária do expressivo contingente populacional que veio para Natal, durante a Segunda Guerra Mundial, e das trasformações ocorridas, demandando não somente moradia, mas também implantando novos hábitos de consumo até à época não praticados pela população do Rio Grande do Norte.

Pela demanda de moradia existente na capital local, na década de 1960, o Estado, por meio da política habitacional, construiu conjuntos habitacionais na Zona Sul e, principalmente na Zona Norte, a fim de garantir moradia para a mão de obra utilizada na indústria resultante da instalação do Distrito Industrial de Natal (DIN), localizado na Zona Norte. Ensejando maior crescimento econômico, outras ações materializaram-se na cidade nas décadas de 1980, 1990 e 2000 por meio de políticas de incentivo industrial e turístico.

Desta forma, principalmente a política habitacional e industrial foram as grandes ações desenvolvidas pelo Estado para a produção do espaço urbano de Natal e ocorreram em concomitância com a chegada do comércio varejista moderno, inicialmente localizado na Zona Sul e que, a posteriori, especializou-se em outras áreas da cidade, inclusive aquelas da Zona Norte, recém incorporadas ao tecido urbano da cidade.

Tem-se, assim, que os diferentes momentos de produção do espaço urbano de Natal nortearam o entendimento da dinâmica comercial das áreas tradicionais de comércio na atualidade, bem como dos demais espaços da cidade, indicando, portanto, uma descentralização da atividade comercial a partir da década de 1980. Em paralelo, tem-se outros processos que se realizam no âmbito da produção do espaço na contemporaneidade e que explicam, associado aos diversos momentos históricos, perspectivas contraditórias e complementares da dinâmica comercial presente e anunciadoras de um porvir mais denso de significados. 
Como é possível perceber, esse cenário que pressupõe a descentralização, modernização e diversidade das atividades comerciais no espaço, quando da construção de novos shopping centers, galerias comerciais e de serviços, redes de supermercados, hipermercados e atacadistas, lojas de departamento, concessionárias de veículos, lojas de eletrodomésticos e de decoração, dentre outras.

Esse comércio, amparado fortemente no varejo moderno, ampliou-se e se diversificou, abrindo espaço, também, para empresas de pequeno e médio porte formais, bem como para a informalidade. De maneira específica, esse comércio de pequeno porte desempenha uma função social de proximidade física e social no seu espaço de atuação por atender majoritariamente a população local ou circunvizinha e também atuar como importante facilitador de relações de confiança e confiabilidade, de modo a reafirmar ainda mais a essência do comércio, baseada no encontro mediado pela troca.

\section{Referências bibliográficas}

BARRETA, João. Fazer acontecer a regeneração urbana: comércio de proximidade. Confederação empresarial de Portugal, 2012.

BRASIL. Ministério do Desenvolvimento, Indústria e Comércio Exterior. Atlas Nacional de Comércio e Serviços. Brasília: MDIC, 2013. Disponível em: http://www.mdic.gov.br/arquivos/dwnl 1414414334.pdf Acesso em: 11 fev. 2016.

COSTA, Ademir Araújo da. A verticalização e as transformações do espaço urbano de Natal-RN. Tese (Doutorado). Universidade Federal do Rio de Janeiro. Instituto de Geociências. Programa de Pós-Graduação em Geografia. Rio de Janeiro, 2000

CRUZ, Rita de Cássia. Políticas de turismo e território. São Paulo: Contexto, 2000.

FERNANDES, José A. Rio; CACHINHO, Herculano; RIBEIRO, Carlos V. (2000) Comércio tradicional em contexto urbano: dinâmicas de modernização e políticas públicas. GEDES, Porto.

FERNANDES, José Alberto Rio. Muitas vidas tem um centro e vários centros tem a vida de uma cidade. In: $A$ nova vida do velho centro nas cidades portuguesas e brasileiras. FERNANDES, José Alberto v. Rio; SPOSITO, Maria Encarnação Beltrão. Porto: Centro de Estudos de Geografia e Ordenamento do Território, 2012.

GOMES, Rita de Cássia da Conceição; SILVA, Anieres Barbosa da; SILVA, Valdenildo Pedro. O setor terciário em Natal. In: VALENÇA, Márcio Moraes; GOMES, Rita de Cássia da Conceição (Org.). Globalização \& desigualdade. Natal, A.S. Editores, 2002. ISBN: 9788588302105

HARVEY, David. A produção capitalista do espaço. Tradução Carlos Szlak. Coordenação Antônio Carlos Robert Moraes. São Paulo: Annablume, 2005. ISBN: 9788574194967.

IBGE. Cadastro Central de $2006 . \quad$ Disponível em: https://sidra.ibge.gov.br/pesquisa/cempre/quadros/brasil/2015 Acesso em: fev. 2016. 
IBGE. Cadastro Central de $2016 . \quad$ Disponível em: https://sidra.ibge.gov.br/pesquisa/cempre/quadros/brasil/2015 Acesso em: fev. 2016.

IBGE Censo demográfico 2010. $2010 . \quad$ Disponível em:
<http://www.ibge.gov.br/home/estatistica/populacao/censo2010/>. Acesso em: 12 jul. 2016.

NATAL, PLANMOB. Expansão urbana de Natal-RN, de 1920-2000, a partir de sua mancha urbana original. 2008. Disponível em: <https://www.planmobnatal.com.br/>. Acesso em: 20 out. 2017.

NATAL. Prefeitura Municipal do Natal. Secretaria Municipal de Tributação (SEMUT). Quantitativo de empresas em Natal. 2016. Ofício no 682/2016GS/SEMUT. Natal, 2016.

ORTIGOZA, Silvia Aparecida Guarniere. Paisagens do consumo: São Paulo, Lisboa, Dubai e Seul. São Paulo: Cultura Acadêmica, 2010. 235 p. Disponível em: <http://www.creasp.org.br/biblioteca/wpcontent/uploads/2012/05/Paisagens_do_consumo.pdf>. Acesso em: 20 out. 2017.

PESSOA, Jomara Dantas. Dinâmicas de reprodução do comércio e os novos papeis urbanos de pequenas cidades norte-rio-grandenses: um olhar a partir das redes associativistas de supermercados. 2015. $244 \mathrm{f}$. Dissertação (Mestrado) - Curso de Geografia, Departamento de Geografia, Universidade Federal do Rio Grande do Norte, Natal, 2015. Cap. $6 . \quad$ Disponível em: <https://repositorio.ufrn.br/jspui/bitstream/123456789/20166/1/JomaraDantasPessoa_DISSERT.pdf>. Acesso em: 25 out. 2017.

PINTAUDI, Silvana Maria. O lugar do supermercado na cidade capitalista. Geografia, UNESP, 1984, v.9, n .1718, pp.37-54.

PINTAUDI, Silvana Maria. A cidade e as formas do comércio. In: CARLOS, Ana Fani Alessandri (Org.). Novos caminhos da Geografia. 6. ed. São Paulo: Contexto, 2013. (Coleção Caminhos da Geografia).

QUEIROZ T. S.; SOUZA T.; GOUVINHAS R. P. Estratégias de marketing como um diferencial na escolha do supermercado de bairro. RAM. Revista de Administração Mackenzie, v. 9, n. 3, São Paulo, maio/junho, 2008.

SALGUEIRO, Teresa Barata. Do comércio à distribuição: roteiro de uma mudança. Oeiras: Celta Editora, 1996.

SALGUEIRO, Teresa Barata; CACHINHO, Herculano. Relações cidade - comércio. Dinâmicas de evolução e modelos interpretativos. In: C. Carreras \& S.M.M Pacheco (Org.). Cidade e Comércio:a rua na perspectiva internacional, Rio de Janeiro, Armazém das Letras, 2009.

SANTOS, Milton. A natureza do espaço: técnica e tempo, razão e emoção. 4. ed. São Paulo:

Editora da Universidade de São Paulo, 2014. 384 p. 8ª reimpressão.

SEBRAE. Cadastro Empresarial do Rio Grande do Norte. 2010. Disponível em: http://www.rn.sebrae.com.br/evento/cemp-cadastro-empresarial/ Acesso em: fev. 2016.

SILVA, Alexsandro Ferreira Cardoso da. O litoral e a metrópole: dinâmica imobiliária, turismo e expansão urbana na Região Metropolitana de Natal/RN. Tese (Doutorado). Universidade Federal do Rio Grande do Norte. Centro de Tecnologia. Programa de Pós-Graduação em Arquitetura e Urbanismo. Natal, 2010.

SPOSITO, Maria Encarnação Beltrão. Segregação sócioespacial e centralidade urbana. In: VASCONCELOS, Pedro de Almeida; CORRÊA, Roberto Lobato; PINTAUDI, Silvana Maria. (Orgs). A cidade contemporânea: segregação especial. São Paulo: Contexto, 2013.

VARGAS. Heliana Comin. Comércio e cidade: Uma relação de origem. Disponível em: http://www.fau.usp.br/depprojeto/labcom/produtos/2000_vargas_comerciocidaderelacaorigem.pdf. Acesso em: set. 2014. 